\title{
Mathematical modeling of the integrated process of mercury bioremediation in the industrial bioreactor
}

\author{
Paweł Głuszcz $\cdot$ Jerzy Petera $\cdot$ Stanisław Ledakowicz
}

Received: 17 June 2010/Accepted: 10 September 2010/Published online: 24 September 2010

(C) The Author(s) 2010. This article is published with open access at Springerlink.com

\begin{abstract}
The mathematical model of the integrated process of mercury contaminated wastewater bioremediation in a fixed-bed industrial bioreactor is presented. An activated carbon packing in the bioreactor plays the role of an adsorbent for ionic mercury and at the same time of a carrier material for immobilization of mercury-reducing bacteria. The model includes three basic stages of the bioremediation process: mass transfer in the liquid phase, adsorption of mercury onto activated carbon and ionic mercury bioreduction to $\mathrm{Hg}(0)$ by immobilized microorganisms. Model calculations were verified using experimental data obtained during the process of industrial wastewater bioremediation in the bioreactor of $1 \mathrm{~m}^{3}$ volume. It was found that the presented model reflects the properties of the real system quite well. Numerical simulation of the bioremediation process confirmed the experimentally observed positive effect of the integration of ionic mercury adsorption and bioreduction in one apparatus.
\end{abstract}

Keywords Mercury · Bioremediation · Process integration · Kinetics · Bioreactor modeling

\section{List of symbols}

$b_{\mathrm{A}} \quad$ Constant in Langmuir equation $\left(\mathrm{dm}^{3} \mathrm{~g}^{-1}\right)$

$c_{\mathrm{A}} \quad$ Mercury concentration inside pores of a sorbent particle $\left(\mathrm{g} \mathrm{dm}^{-3}\right)$

$C_{\mathrm{A}} \quad$ Mercury concentration in liquid in the bioreactor $\left(\mathrm{g} \mathrm{dm}^{-3}\right)$

$D_{\mathrm{AL}} \quad$ Longitudinal dispersion coefficient in the bioreactor $\left(\mathrm{m}^{2} \mathrm{~s}^{-1}\right)$

P. Głuszcz $\cdot$ J. Petera $\cdot$ S. Ledakowicz $(\bowtie)$

Faculty of Process and Environmental Engineering, Technical University of Lodz, Wólczańska 213, 90-924 Lodz, Poland

e-mail: stanleda@p.lodz.pl
$D_{\text {Ap }} \quad$ Effective diffusion coefficient inside a particle $\left(\mathrm{m}^{2} \mathrm{~s}^{-1}\right)$

$D_{\mathrm{AR}} \quad$ Radial dispersion coefficient in the bioreactor $\left(\mathrm{m}^{2} \mathrm{~s}^{-1}\right)$

$D_{\text {Aw }}$ Diffusion coefficient of mercury in water $\left(\mathrm{m}^{2} \mathrm{~s}^{-1}\right)$

$k_{f} \quad$ Mass transfer coefficient in a liquid phase $\left(\mathrm{m} \mathrm{s}^{-1}\right)$

$K_{\mathrm{I}} \quad$ Inhibition constant $\left(\mathrm{mg} \mathrm{dm}^{-3}\right)$

$K_{\mathrm{S}} \quad$ Saturation constant $\left(\mathrm{mg} \mathrm{dm}^{-3}\right)$

$M_{\mathrm{W}} \quad$ Water molar mass $\left(\mathrm{g} \mathrm{mol}^{-1}\right)$

$q_{\mathrm{A}} \quad$ Amount of mercury adsorbed ( $\mathrm{mg} \mathrm{g}^{-1}$ )

$q_{\mathrm{Am}} \quad$ Maximum saturation sorption capacity of the activated carbon $\left(\mathrm{mg} \mathrm{g}^{-1}\right)$

$r \quad$ Radius (m)

$R_{\mathrm{A}} \quad$ Bioreduction reaction rate $\left(\mathrm{mg} \mathrm{min} \mathrm{mim}^{-1} \mathrm{dm}^{-3}\right.$

$R_{\mathrm{p}} \quad$ Particle radius (m)

$T$ Temperature (K)

$t \quad$ Time (s)

$V_{\mathrm{A}} \quad$ Mercury molar volume $\left(\mathrm{dm}^{3} \mathrm{~mol}^{-1}\right)$

$v_{\max }$ Maximum specific reaction rate $\left(\mathrm{mg} \min ^{-1} \mathrm{~g}^{-1}\right.$ )

$v_{r} \quad$ Radial liquid velocity in bioreactor $\left(\mathrm{m} \mathrm{s}^{-1}\right)$

$v_{z} \quad$ Linear superficial liquid velocity in bioreactor $\left(\mathrm{m} \mathrm{s}^{-1}\right)$

$\varepsilon \quad$ Porosity of the bed in the bioreactor

$\varepsilon_{\mathrm{p}} \quad$ Porosity of a sorbent particle

$\varphi_{\mathrm{W}} \quad$ Water association coefficient

$\mu_{\mathrm{W}} \quad$ Liquid (water) viscosity (Pa s)

$\rho \quad$ Liquid density $\left(\mathrm{g} \mathrm{dm}^{-3}\right)$

$\rho_{\text {bi }} \quad$ Biomass concentration $\left(\mathrm{g} \mathrm{dm}^{-3}\right)$

$\rho_{\mathrm{s}} \quad$ Density of the sorbent $\left(\mathrm{g} \mathrm{dm}^{-3}\right)$

\section{Introduction}

Extensive industrial use of mercury has led to significant pollution of the environment. Anthropogenic sources of mercury are numerous and worldwide. Its unique physical 
properties (heavy liquid) at room temperature has enabled the use of mercury for a variety of purposes such as in mercury switches, thermostats, thermometers, pressure gauges, barometers and batteries. Its toxic properties have made possible its use as medication, in pesticides and in antiseptic materials. Other applications of mercury include dental amalgams, energy-efficient lamps, pigments, amalgam technology in chlor-alkali industry and gold mining.

Presently, the major industrial sources of mercury emissions to the environment include the burning of coal to produce electricity, the incineration of waste and the amalgam chlor-alkali technology. The chlor-alkali industry produces chlorine and alkali, sodium hydroxide or potassium hydroxide by electrolysis of brine. There are three different techniques based on brine electrolysis, but mercury emission is specific only for the mercury-cell technology. It has been in use, mainly in Europe since 1892, and in the year 2009 it accounted for about $35 \%$ of total production of about 10 million tons per year of chlorine in Europe [1].

Due to the mercury-cell technology characteristics, mercury can be emitted to the environment through air, water, solid wastes and in products. Total mercury emission from chlor-alkali plants in Europe was about 30 tons in 2009, ranging from 0.2 to $3.0 \mathrm{~g} \mathrm{Hg}$ per ton of chlorine produced in the individual plants [1]. It must be underlined that mercury is a global pollutant due to atmospheric transport throughout the world and accumulation in the food chain. Therefore, removal of mercury from industrial emissions in all possible places is mandatory and should take into account the latest achievements in science and technology.

For mercury remediation from industrial wastewaters, a unique biotechnological method based on the enzymatic reduction of $\mathrm{Hg}(\mathrm{II})$ compounds to water-insoluble $\mathrm{Hg}(0)$ by live mercury-resistant bacteria has been proposed by the Helmholtz Centre for Infection Research, HZI, the former German Research Centre for Biotechnology (GBF) [2]. The technology was then developed at the Technical University of Lodz (TUL), Poland, by process integration of the mercury bioreduction and adsorption onto activated carbon filling a fixed-bed bioreactor [3]. The integrated bioremediation technology was applied at the industrial scale in one of the Polish chemical companies in Tarnow, Poland, for mercury removal from wastewater coming from a chlor-alkali plant [4].

\section{Experimental setup}

The core of the technological process developed at TUL is a $1 \mathrm{~m}^{3}$ packed-bed bioreactor with granulated activated carbon as a carrier material for microorganisms and, at the same time, adsorbent for mercury. The basic dimensions of the fixed bed are the diameter of $1 \mathrm{~m}$ and height of $1.27 \mathrm{~m}$. The microorganisms immobilized in the bioreactor are natural, not pathogenic soil bacteria that possess a natural mercury resistance. The strain used in the experiments was Pseudomonas putida Spi3. The ionic mercury MIC for this strain was $5 \mathrm{mg} / \mathrm{l}$ and the MBC was $75 \mathrm{mg} / \mathrm{l}$.

The bacteria convert enzymatically reactive ionic mercury to elemental mercury, which remains in the packed bed of the bioreactor as water-insoluble metal and is no longer toxic for the bacteria. The secreted metallic mercury, which accumulates in the form of small droplets, is retained in the activated carbon packing in the bioreactor. If the bioreactor is saturated with mercury (after approximately 2 years of operation), the packed-bed material may be removed and deposited or the metallic mercury could be recovered by distillation. The description of the whole experimental plant has been provided elsewhere [5].

The integrated installation was used for 18 months for cleaning all the wastewater from the Tarnow chlor-alkali plant. The volumetric flow rate of the wastewater was in the range of $0.8-1.8 \mathrm{~m}^{3} \mathrm{~h}^{-1}$, inlet mercury concentration changed from 1.5 to $10 \mathrm{mg} \mathrm{dm}^{-3}$, and the average outlet mercury concentration from the bioreactor was in the range of $120-300 \mu \mathrm{g} \mathrm{dm}^{-3}$. The experimental data obtained during the operation of this industrial bioreactor were used for verification of the presented mathematical model of the process.

\section{Mathematical model of the integrated process}

Proper design, optimization and simulation of the integrated bioremediation process require a reliable mathematical model to be used. In this study, a relatively simple model taking into account bioreduction of ionic mercury and at the same time its adsorption onto activated carbon has been developed and verified experimentally.

The model includes three basic stages of the bioremediation process: mass transfer in the liquid phase, adsorption of mercury onto activated carbon and ionic mercury bioreduction by immobilized microorganisms. The mass transfer takes into account transport of the solute in the liquid phase along the bioreactor, mass transfer in the liquid film at the surface of the sorbent particle, diffusion in the liquid phase within the pores of the particle and sorption onto the adsorbent surface. Each of these partial processes is described by different equations and characterized by different kinetic parameters. Additionally, at the surface of the activated carbon, the bioreduction process takes place with the ionic mercury as a substrate and metallic mercury as a product of the reaction. It is assumed that metallic mercury is non-soluble and precipitates from the liquid phase just after the reaction. 
The following assumptions were also made for the formulation of model equations:

- total mass transfer resistance is placed only within the boundary layer at the sorbent particle surface and it is characterized by a film mass transfer coefficient for the diffusion in the direction normal to the particle surface;

- mercury transport inside pores of a sorbent particle occurs only by diffusion;

- the adsorption process is much faster than mass transfer in the liquid phase and the equilibrium conditions prevail at the solid particle surface;

- the adsorption process is isothermal;

- sorption equilibrium is represented by the Langmuir isotherm;

- diffusion coefficient inside particle pores is concentration independent;

- sorbent particles are spherical and uniform in radius and density;

- the liquid flow along the bed is not an ideal plug flow and it may be characterized by a longitudinal dispersion coefficient, $D_{\mathrm{L}}$;

- the bioreduction reaction takes place only within pores of solid particles and its rate depends on the local concentration of ionic mercury along the particle radius.

Mass balance within a single sorbent particle is represented by the equation:

$\frac{\partial c_{\mathrm{A}}}{\partial t}+\left(\frac{1-\varepsilon_{\mathrm{p}}}{\varepsilon_{\mathrm{p}}}\right) \rho_{s} \frac{\partial q_{\mathrm{A}}}{\partial t}=D_{\mathrm{Ap}} \frac{1}{r^{2}} \frac{\partial}{\partial r}\left(r^{2} \frac{\partial c_{\mathrm{A}}}{\partial r}\right)-R_{\mathrm{A}}$

Taking into account the assumption that the rate of the adsorption process is much higher than pore diffusion and applying the Langmuir isotherm:

$\frac{q_{\mathrm{A}}}{q_{\mathrm{Am}}}=\frac{b_{\mathrm{A}} c_{\mathrm{A}}}{1+b_{\mathrm{A}} c_{\mathrm{A}}}$

for the liquid-solid equilibrium at the sorbent pores surface, the following expression may be written:

$\frac{\partial q_{\mathrm{A}}}{\partial t}=\frac{\partial q_{\mathrm{A}}}{\partial c_{\mathrm{A}}} \frac{\partial c_{\mathrm{A}}}{\partial t}=\frac{b_{\mathrm{A}} q_{\mathrm{Am}}}{\left(1+b_{\mathrm{A}} c_{\mathrm{A}}\right)^{2}} \frac{\partial c_{\mathrm{A}}}{\partial t}$

The bioreduction reaction rate is given by the expression:

$R_{\mathrm{A}}=\frac{v_{\max } \rho_{\mathrm{bi}}}{1+K_{\mathrm{S}} / c_{\mathrm{A}}+\left(c_{\mathrm{A}} / K_{\mathrm{I}}\right)^{2}}$

which is the modified Haldane model for the substrateinhibited reaction [6]. If $R_{\mathrm{A}}=0$ then the mathematical model of the process describes the pure adsorption of the ionic mercury onto activated carbon in the bioreactor. The symbol $\rho_{\text {bi }}$ in the Eq. 4 represents biomass density, which may vary during the process as an effect of biomass growth or decay. These effects will be discussed later.
Hence, the final expression for the mass balance of the substrate in the sorbent particle has a form:

$$
\begin{aligned}
& {\left[1+\left(\frac{1-\varepsilon_{\mathrm{p}}}{\varepsilon_{\mathrm{p}}}\right) \frac{b_{\mathrm{A}} q_{\mathrm{Am}} \rho_{\mathrm{s}}}{\left(1+b_{\mathrm{A}} c_{\mathrm{A}}\right)^{2}}\right] \frac{\partial c_{\mathrm{A}}}{\partial t}=D_{\mathrm{Ap}} \frac{1}{r^{2}} \frac{\partial}{\partial r}\left(r^{2} \frac{\partial c_{\mathrm{A}}}{\partial r}\right)} \\
& \quad-\frac{v_{\max } \rho_{\mathrm{bi}}}{1+K_{\mathrm{S}} / c_{\mathrm{A}}+\left(c_{\mathrm{A}} / K_{\mathrm{I}}\right)^{2}}
\end{aligned}
$$

The boundary conditions applied for the above equation are as follows $(t \geq 0)$ :

$$
\begin{aligned}
& \left.\frac{\partial c_{\mathrm{A}}}{\partial r}\right|_{r=0}=0 \\
& -\left.D_{\mathrm{Ap}} \frac{\partial c_{\mathrm{A}}}{\partial r}\right|_{r=R_{\mathrm{p}}}=k_{f}\left(C_{\mathrm{A}}-\left.c_{\mathrm{A}}\right|_{r=R_{\mathrm{p}}}\right)
\end{aligned}
$$

The condition (6b) describes continuity of two mass fluxes at the liquid-solid interfacial surface: one of them resulting from the diffusion from the external particle surface to its inside and the other resulting from the film mass transfer to the particle surface in the liquid phase.

The equation for the mass balance of the solute in the liquid flowing along the bed height may be written in the form:

$$
\begin{gathered}
\frac{\partial C_{\mathrm{A}}}{\partial t}+v_{r} \frac{\partial C_{\mathrm{A}}}{\partial r}+v_{z} \frac{\partial C_{\mathrm{A}}}{\partial z}=D_{\mathrm{AR}} \frac{1}{r^{2}} \frac{\partial}{\partial r}\left(r^{2} \frac{\partial C_{\mathrm{A}}}{\partial r}\right) \\
+D_{\mathrm{AL}} \frac{\partial^{2} C_{\mathrm{A}}}{\partial z^{2}}-\frac{1-\varepsilon}{\varepsilon} \rho_{\mathrm{s}} \frac{d \bar{q}_{\mathrm{A}}}{d t}
\end{gathered}
$$

The mass balance of the substrate at the surface between the spherical solid particle and the liquid may be expressed as:

$\frac{d \bar{q}_{\mathrm{A}}}{d t}=\left(\frac{3 k_{f}}{\rho_{\mathrm{s}} R_{\mathrm{p}}}\right)\left(C_{\mathrm{A}}-\left.c_{\mathrm{A}}\right|_{r=R_{\mathrm{p}}}\right)$

Taking this into account, the Eq. 7 may be transformed to the final form:

$$
\begin{aligned}
\frac{\partial C_{\mathrm{A}}}{\partial t} & +v_{r} \frac{\partial C_{\mathrm{A}}}{\partial r}+v_{z} \frac{\partial C_{\mathrm{A}}}{\partial z}=D_{\mathrm{AR}} \frac{1}{r^{2}} \frac{\partial}{\partial r}\left(r^{2} \frac{\partial C_{\mathrm{A}}}{\partial r}\right) \\
& +D_{\mathrm{AL}} \frac{\partial^{2} C_{\mathrm{A}}}{\partial z^{2}}-\frac{1-\varepsilon}{\varepsilon} \frac{3 k_{\mathrm{f}}}{R_{\mathrm{p}}}\left(C_{\mathrm{A}}-\left.c_{\mathrm{A}}\right|_{r=R_{\mathrm{p}}}\right)
\end{aligned}
$$

Boundary conditions may be defined as follows:

- for the inlet of the bioreactor (Danckwert's condition):

$-\left.D_{\mathrm{AL}} \frac{\partial C_{\mathrm{A}}}{\partial z}\right|_{z=0}=v_{z}\left(C_{\mathrm{A} 0}-\left.C_{\mathrm{A}}\right|_{z=0}\right)$

- for the outlet of the bioreactor:

$\left.\frac{\partial C_{\mathrm{A}}}{\partial z}\right|_{z=L}=0$

Initial conditions are as follows $(t=0)$ :

$c_{\mathrm{A}}=0 \quad$ for $0 \leq r \leq R_{\mathrm{p}}$ 
$C_{\mathrm{A}}=0 \quad$ for $0 \leq z \leq L$

The velocity field in the bioreactor was calculated on the basis of a well-known equation of momentum and mass preservation (global, of the solution in the bioreactor) in the porous bed [7]. The vector equation of the momentum preservation has then the form:

$\frac{\partial(\varepsilon \rho \mathbf{v})}{\partial t}+\nabla \cdot(\varepsilon \rho \mathbf{v v})=-\varepsilon \nabla p+\nabla \cdot(\varepsilon \tau)+\varepsilon \mathbf{g}-\frac{\mu}{\alpha} \mathbf{v}$

where $\mathbf{v}$ it is the velocity vector in the pores of the bed, $\rho$ is the liquid density, $p$ is the pressure, $\tau$ is the stress tensor, $\mathbf{g}$ is the gravity vector and $\alpha$ is the permeability coefficient of the bed, given by the expression resulting from the Karman-Kozeny model [7]:

$\alpha=\frac{\left(2 R_{\mathrm{p}} \varepsilon\right)^{2}}{90(1-\varepsilon)}$

The equation of mass preservation (continuity equation) may be written as:

$\frac{\partial(\varepsilon \rho)}{\partial t}+\nabla \cdot(\varepsilon \rho \mathbf{v})=0$

The boundary conditions are as follows:

$\mathbf{v}=\mathbf{0}$ for the wall

$\mathbf{v}=\left[0,0, v_{0}\right]$ at the inlet

$\tau \cdot \mathbf{n}=\mathbf{0}, p=0 \quad$ at the outlet from the bioreactor.

The initial condition is:

$\mathbf{v}=\mathbf{0}$ in the whole bioreactor for the time $t=0$

The problem of mass transfer in the integrated bioreactor, described by the above model, was solved by the finite element method in the non-steady regime using "twoscaled" approach, i.e. taking into account "macro" and "micro" scale of the bioremediation process.

In the "macro" scale, the equations for the momentum and mass preservation for the components were solved in a common way, as transport of these quantities in a porous bed, according to the Eqs. 7-16.

In the "micro" scale the Eqs. 1-6a, 6b were solved as the diffusive transport and the adsorption with the reaction in the one-dimensional calculation domain corresponding to the radial direction within adsorbent particles.

There is certainly a feedback between equations in the "macro" and "micro" scale, as the concentration $c_{\mathrm{A}}$ occurs in the "macro" scale Eq. 9, and the concentration $C_{\mathrm{A}}$ is present in the boundary condition (6b) for the solution of the "micro" scale equation; therefore, these equations were solved alternately in consecutive time intervals.

\section{Estimation of the basic parameters}

The above model was used for simulation of the mercury bioremediation process in the industrial bioreactor. In particular, the changes of the outlet mercury concentration $C_{\mathrm{A}}(t)_{z=L}$ resulting from the changes of the process parameters were predicted. Certainly, before any calculations, the model parameters must have been identified.

Some of the model parameters, in particular those concerning the basic properties of the system, were known or obtained experimentally. The density and the porosity of the activated carbon particle were given by the producer (Carbon-Racibórz, Poland), and were $\rho_{\mathrm{s}}=2.5 \times 10^{3} \mathrm{~kg} \mathrm{~m}^{-3}$ and $\varepsilon_{\mathrm{p}}=0.57$, respectively. It was assumed that the density and viscosity of the wastewater is the same as of water, so in the calculations the values of the liquid density $\rho=1.0 \times 10^{3} \mathrm{~kg} \mathrm{~m}^{-3}$ and viscosity $\mu_{\mathrm{W}}=1.0 \times$ $10^{-3} \mathrm{~Pa}$ s were applied. The chlor-alkali wastewater is in fact wash water from the electrolysis hall and rainwater collected from the terrain around the hall. Before entering the bioreactor, the wastewater is thoroughly filtered and diluted with clean water to lower $\mathrm{Hg}$ concentration below $5 \mathrm{mg} / \mathrm{l}$. Hence, the assumption about the wastewater density seems to be reasonable. Moreover, it was checked that changes of the liquid density in the range $\pm 10 \%$ practically have no influence on the simulation results. Porosity of the bed was obtained experimentally by measuring the amount of water filling the wet packing of the known volume. It was found that the porosity of the bed was $\varepsilon=0.4$.

Superficial liquid velocity in the bioreactor was calculated on the basis of a volumetric flow rate of wastewater; e.g. for the nominal flow rate of $1 \mathrm{~m}^{3} \mathrm{~h}^{-1}$, the linear superficial liquid velocity in the bioreactor was $v_{z}=3.5 \times$ $10^{-4} \mathrm{~m} \mathrm{~s}^{-1}$.

The parameters of the Langmuir Eq. 2 were identified using experimental sorption isotherms obtained for the activated carbon used as a packing in the bioreactor. The following values were found: equilibrium saturation capacity $q_{\mathrm{Am}}=1.754 \times 10^{2} \mathrm{mg} \mathrm{g}^{-1}$ and the equilibrium constant $b_{\mathrm{A}}=5.4 \times 10^{-3} \mathrm{dm}^{3} \mathrm{~g}^{-1}$.

Diffusion coefficient in the pores of the sorbent particle was estimated on the basis of the results of previous investigations [8], where the kinetic parameters of the mercury sorption process for different types of activated carbon were identified. It was found that irrespective of the type of activated carbon, diffusion coefficients are similar within the same order of magnitude, so the value of $D_{\mathrm{Ap}}=10^{-9} \mathrm{~m}^{2} \mathrm{~s}^{-1}$ was applied in the model calculations.

The film mass transfer coefficient $k_{f}$ was calculated from the correlation of Wilson and Geankoplis [9]:

$S h=(1.09 / \varepsilon) S c^{1 / 3} R e^{1 / 3}$ 


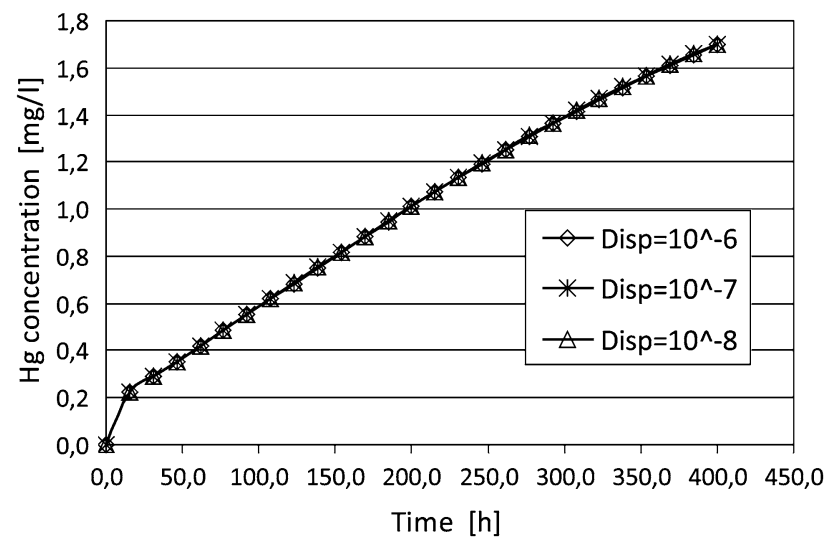

Fig. 1 Initial part of breakthrough curves in the industrial bioreactor at the beginning of the adsorption process calculated for three different values of $D_{\mathrm{AL}}\left(D_{\mathrm{AL}}=10^{-8} \mathrm{~m}^{2} \mathrm{~s}^{-1}, D_{\mathrm{AL}}=10^{-7} \mathrm{~m}^{2} \mathrm{~s}^{-1}\right.$, $D_{\mathrm{AL}}=10^{-6} \mathrm{~m}^{2} \mathrm{~s}^{-1}$ )

where the diffusion coefficient of the ionic mercury in the liquid phase was obtained from the Wilke-Chang semiempirical equation [9]:

$D_{\mathrm{AW}}=\frac{7.4 \times 10^{-8}\left(\varphi_{\mathrm{W}} M_{\mathrm{W}}\right)^{1 / 2} T}{\mu_{\mathrm{W}} V_{\mathrm{A}}^{0.6}}$

The calculated value of the diffusion coefficient was $3.0 \times 10^{-9} \mathrm{~m}^{2} \mathrm{~s}^{-1}$ and the mass transfer coefficient was $k_{f}=2.43 \times 10^{-5} \mathrm{~m} \mathrm{~s}^{-1}$.

The longitudinal dispersion coefficient was assumed to be $D_{\mathrm{AL}}=10^{-8} \mathrm{~m}^{2} \mathrm{~s}^{-1}$, as it was obtained in the abovementioned previous investigations [8]. Although $D_{\mathrm{AL}}$ value cannot be directly transferred from a laboratory to an industrial scale apparatus, it was proved by the simulation of the adsorption process that this parameter had little effect on the final results of the model calculations, so its value may be assumed as constant with a wide margin of error. Figure 1 shows that there is no influence of the $D_{\mathrm{AL}}$ coefficient on the adsorption process in the industrial bioreactor in the applied range of values.

\section{Estimation of the kinetic parameters of the mercury bioreduction reaction}

The mercury bioreduction rate in the model of the integrated process is described by the Eq. 4. The kinetic parameters of this equation were adopted from the experimental investigations concerning mercury bioreduction by $P$. putida strain in a laboratory bioreactor [10]. Although conditions prevailing in the industrial apparatus were different than in laboratory scale, the following values were taken as the initial ones for the mathematical model verification: $v_{\max }=38.64 \mathrm{mg} \mathrm{min}^{-1} \mathrm{~g}^{-1}, K_{\mathrm{S}}=4.52 \mathrm{mg} \mathrm{dm}^{-3}$, $K_{\mathrm{I}}=0.62 \mathrm{mg} \mathrm{dm}^{-3}$.
The maximum value of the biomass density, $\rho_{\mathrm{bi}}$, was estimated on the basis of experiments in a laboratory fixedbed activated carbon bioreactor where the process of mercury bioremediation was also investigated. In these experiments, the biomass immobilized on the activated carbon of the same type as in industrial scale as well as suspended in the liquid filling the bioreactor was taken into account. Using the Lowry method, the amount of protein in the samples of activated carbon taken from different levels of the bioreactor was determined and then the biomass concentration was calculated assuming that protein accounts for $55 \%$ of the total biomass [11]. The estimated value of biomass immobilized in the activated carbon bed was $\rho_{\mathrm{bm}}=5.7 \mathrm{~kg} \mathrm{~m}^{-3}$.

Preliminary simulations of the integrated process showed that the bioreduction reaction plays a dominant role in the total effect of mercury removal in comparison to its adsorption onto activated carbon. If the above values of the kinetic parameters were used, the simulated outlet concentration of mercury dropped to zero, which did not comply with the experimental results obtained in the industrial bioreactor. Obviously, the applied $v_{\max }$ parameter value was too high for the real bioremediation process. The proper value of $v_{\max }$ was then identified from experimental results using the model of the process in the following way. During the industrial bioreactor operation, it was observed that if the inlet mercury concentration had a constant value of $2.5 \mathrm{mg} \mathrm{dm}^{-3}$ for some time, the outlet concentration was maintained at a constant level of about $0.2 \mathrm{mg} \mathrm{dm}^{-3}$ (Fig. 2).

Taking this into account, the reverse analysis of the model enabled estimation of the $v_{\max }$, which fitted the above conditions. The estimated value was $v_{\max }=$ $5.9 \mathrm{mg} \mathrm{min}{ }^{-1} \mathrm{~g}^{-1}$; the other kinetic parameters of the Eq. 4 have little influence on the outlet concentration of mercury, so they were left unchanged for the purpose of simulation.

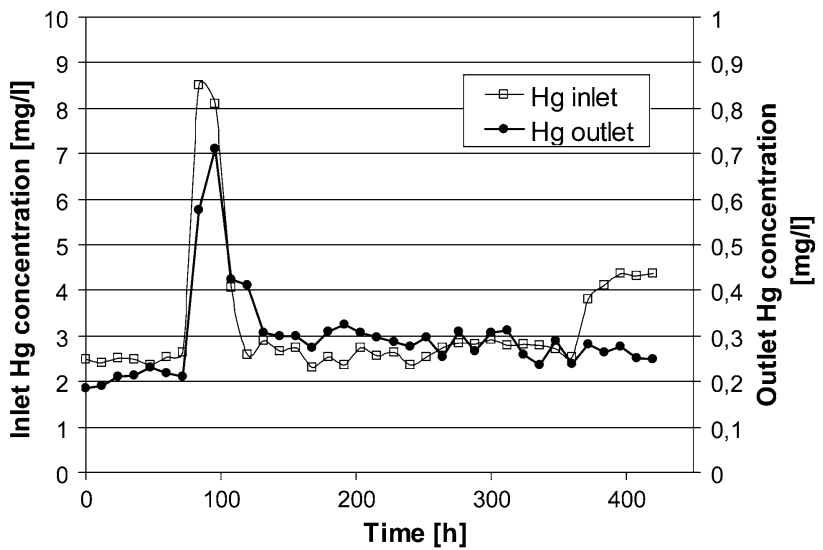

Fig. 2 Changes of mercury outlet concentration in the industrial bioreactor during temporary increase of $\mathrm{Hg}$ concentration at the inlet 


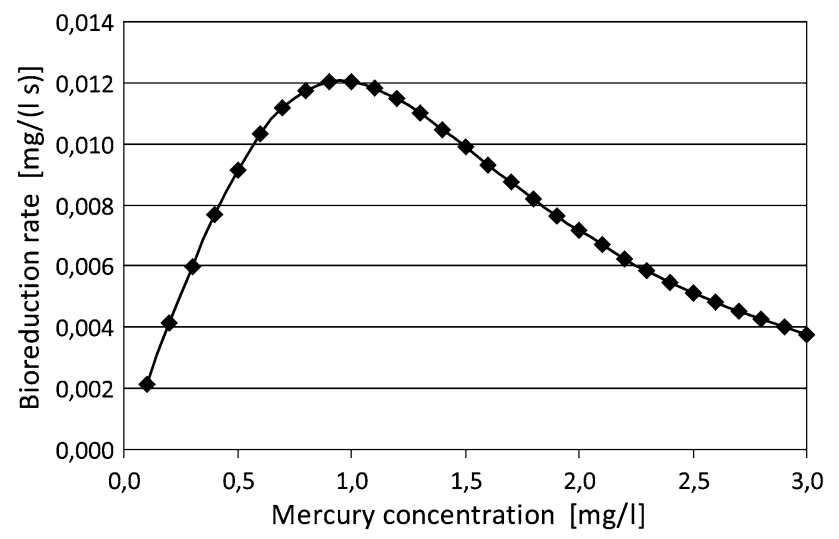

Fig. 3 The influence of the mercury concentration on the bioreduction rate

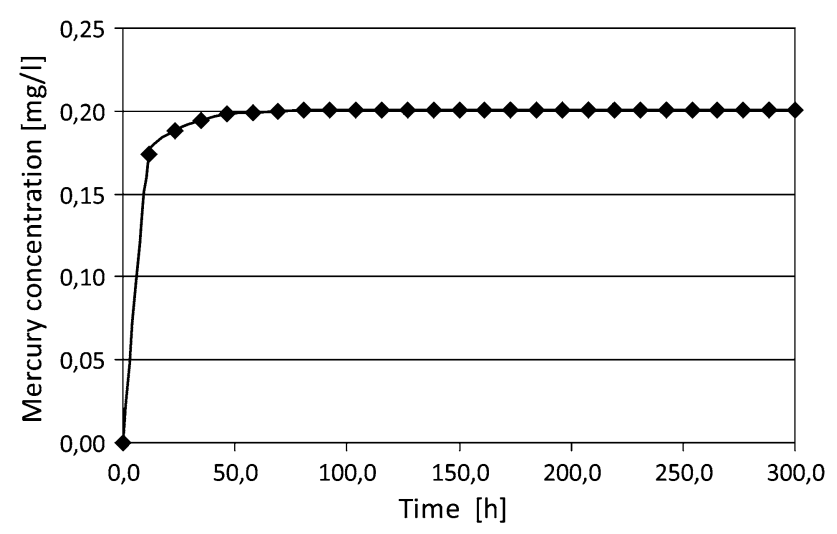

Fig. 4 Changes of the outlet mercury concentration at the beginning of the bioremediation process (inlet mercury concentration $2.5 \mathrm{mg} \mathrm{dm}^{-3}$, constant biomass density)

In Fig. 3, the influence of the substrate (ionic mercury) concentration $C_{\mathrm{A}}$ on the bioreduction rate according to the Eq. 4 with the above values of the parameters is presented. The reaction rate has the maximum at the mercury concentration of $1 \mathrm{mg} \mathrm{dm}^{-3}$, and then decreases due to the effect of substrate inhibition.

Changes of the mercury concentration at the outlet of the bioreactor, for the same model parameters and the inlet concentration of $2.5 \mathrm{mg} \mathrm{dm}^{-3}$, is presented in Fig. 4 .

From the graph, it may be concluded that if the constant biomass concentration in the bioreactor is assumed, the outlet mercury concentration reaches a constant value of $0.2 \mathrm{mg} \mathrm{dm}^{-3}$ after a relatively short time of about $50 \mathrm{~h}$ from the beginning of the process.

\section{Influence of the operational conditions on the bioremediation process}

An important problem that may be clarified by numerical simulation of the process is the influence of basic

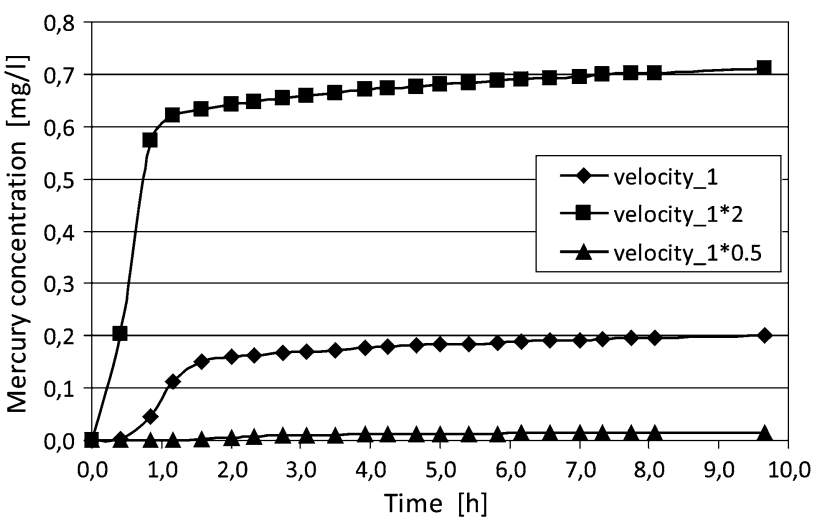

Fig. 5 Influence of the wastewater flow rate on the outlet mercury concentration

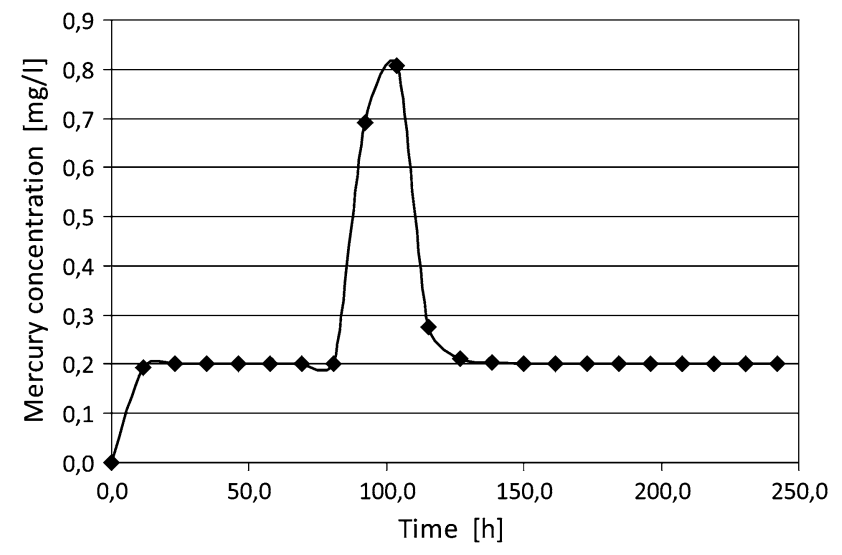

Fig. 6 Simulated changes of the outlet mercury concentration after temporary increase of the mercury concentration at the inlet

operational conditions on the bioremediation efficiency. In Fig. 5, the influence of the wastewater flow rate on the outlet mercury concentration is presented, for the inlet $\mathrm{Hg}$ concentration of $2.5 \mathrm{mg} \mathrm{dm}^{-3}$ and the nominal liquid velocity $v_{z}=3.5 \times 10^{-4} \mathrm{~m} \mathrm{~s}^{-1}$.

The graph shows that doubling the nominal value of the liquid velocity leads to more than proportional increase of the unreacted substrate concentration at the outlet of the bioreactor; the concentration increases from about 0.2 $\mathrm{mg} \mathrm{dm}{ }^{-3}$ at the nominal liquid velocity to $0.7 \mathrm{mg} \mathrm{dm}^{-3}$ at its doubled value. In turn, decreasing the liquid velocity two times gives the outlet mercury concentration close to zero. From this simulation, one may conclude that the system is very sensitive to wastewater flow rate and it is very important to control this parameter precisely in the real process.

The response of the system to changes of the inlet mercury concentration is presented in Fig. 6. The course of the simulated experiment was as follows. At the inlet of the bioreactor, the constant mercury concentration of $2.5 \mathrm{mg} \mathrm{dm}^{-3}$ was kept from the beginning of the process 
until the constant outlet concentration of about $0.2 \mathrm{mg} \mathrm{dm}^{-3}$ was obtained. Then the inlet concentration was raised to $10 \mathrm{mg} \mathrm{dm}^{-3}$ for $20 \mathrm{~h}$, and thereafter it was decreased again to $2.5 \mathrm{mg} \mathrm{dm}^{-3}$. Such changes of the $\mathrm{Hg}$ concentration were observed several times in practice, so the simulation followed the real experiment (see Fig. 2). Figure 6 shows that if the constant concentration of biomass may be assumed, the system preserves its ability to ionic mercury reduction and the outlet concentration drops again to a constant value of $0.2 \mathrm{mg} \mathrm{dm}^{-3}$ after a transient increase to $0.8 \mathrm{mg} \mathrm{dm}^{-3}$ during the impulse disturbance at the inlet.

In practice, it was observed that after the temporary disturbance of the inlet $\mathrm{Hg}$ concentration, the outlet mercury concentration did not fall down exactly to the previous value and remained at the increased level of about $0.3 \mathrm{mg} \mathrm{dm}^{-3}$ for some time. This effect might indicate the partial deactivation of biomass caused by temporarily increased toxicity of the wastewater. This conclusion led to the idea of modification of the model by introducing equations for biomass growth and decay in the mathematical model of the process.

\section{Modification of the kinetic model of the bioreduction reaction}

In the model discussed above, it was assumed that biomass concentration was constant in the course of the bioremediation process. In practice, as the experimental observations show, the biomass concentration changes with time.

Firstly, it increases, at least at the beginning of the process, as a result of biomass growth. It may be described by one of the growth models, e.g. the logistic model of Verlhurst:

$\frac{d \rho_{\mathrm{bi}}}{d t}=\mu_{n} \rho_{\mathrm{bi}}\left(1-\frac{\rho_{\mathrm{bi}}}{\rho_{\mathrm{bm}}}\right)$

According to the solution of this equation with the initial condition $\rho_{\mathrm{bi}}=\rho_{\mathrm{b} 0}$ for $t=0$, the biomass reaches the final, maximum constant concentration $\rho_{\text {bm }}$ after a long enough time. In the experimental bioreactor, it was:

$\rho_{\mathrm{bi}} \stackrel{t \rightarrow \infty}{\longrightarrow} \rho_{\mathrm{bm}}=5.7 \mathrm{~g} \mathrm{dm}^{-3}$

The $\mu_{n}$ parameter is in fact a specific maximal growth rate of the microorganisms, and in the model it characterizes the rate of reaching the maximum value of biomass density. For the model calculations, two different $\mu_{n}$ values were applied, consistent in terms of order of magnitude with the data for bacteria growth in industrial conditions [12]; these two values were: $\mu_{n}=1 / 30 \mathrm{~h}^{-1}$ and $\mu_{n}=1 /$ $10 \mathrm{~h}^{-1}$.

Secondly, the active biomass concentration may decrease during the process, as a result of a toxic substrate influence, e.g. after significant increase of mercury concentration at the inlet. To take it into account, Eq. 19 was supplemented with the term representing biomass decay. The changes of biomass concentration are expressed then by the following equation:

$\frac{d \rho_{\mathrm{bi}}}{d t}=\mu_{n}\left[\rho_{\mathrm{bi}}\left(1-\frac{\rho_{\mathrm{bi}}}{\rho_{\mathrm{bm}}}\right)-\beta c_{\mathrm{A}}\right]$

where $c_{\mathrm{A}}$ is the local mercury concentration in the bioreactor and $\beta$ is a new kinetic parameter, taking into account biomass deactivation resulting from the increased toxicity of the solution. After such modification, Eq. 21 may be considered as a full "growth-decay" model, where the first, positive term accounts for the biomass concentration increase and the second, with the negative sign, accounts for the microorganisms deactivation.

The experimental results obtained in the industrial bioreactor enabled estimation of the parameter $\beta$. The data collected during the experiment with temporary increase of the inlet mercury concentration were used for that. As mentioned earlier, if the inlet mercury concentration was raised from 2.5 to $10 \mathrm{mg} \mathrm{dm}^{-3}$ for $20 \mathrm{~h}$ and then decreased to its initial value, the outlet concentration increased from a constant value of $0.2 \mathrm{mg} \mathrm{dm}^{-3}$, went through the maximum of about $0.7 \mathrm{mg} \mathrm{dm}^{-3}$ and then fell down but not to the initial value of $0.2 \mathrm{mg} \mathrm{dm}^{-3}$ but to the higher level of $0.3 \mathrm{mg} \mathrm{dm}^{-3}$ (Fig. 2) These data used together with the modified model including the biomass "growth-decay" equation enabled identification of the $\beta$ parameter satisfying the process conditions. The following values were obtained for two different values of $\mu_{n}$ applied earlier:

$\beta=5.4\left[\frac{g_{\text {bio }}}{g_{\mathrm{Hg}^{++}}}\right] \quad$ for $\mu_{n}=1 / 30 \mathrm{~h}^{-1}$

and

$\beta=4.5\left[\frac{g_{\text {bio }}}{g_{\mathrm{Hg}^{++}}}\right] \quad$ for $\mu_{n}=1 / 10 \mathrm{~h}^{-1}$

Figure 7 shows simulated changes of the outlet mercury concentration during the described experiment. The calculations were done for $\mu_{n}=1 / 30 \mathrm{~h}^{-1}$ and the appropriate value of $\beta$. Additionally, the simulation was done for two different values of Langmuir equation parameters (i.e. in fact, for two types of activated carbon) to check the influence of adsorption on the integrated process.

From the graph, it may be concluded that adsorption parameters of the activated carbon have significant influence on the bioremediation process. When the smaller value of carbon saturation capacity, $q_{m}$, is applied, the outlet mercury concentration after the impulse disturbance at the inlet goes to a value higher than $0.4 \mathrm{mg} \mathrm{dm}^{-3}$. The greater value of $q_{m}$, specific for the activated carbon used in practice in the industrial bioreactor gives the final outlet 


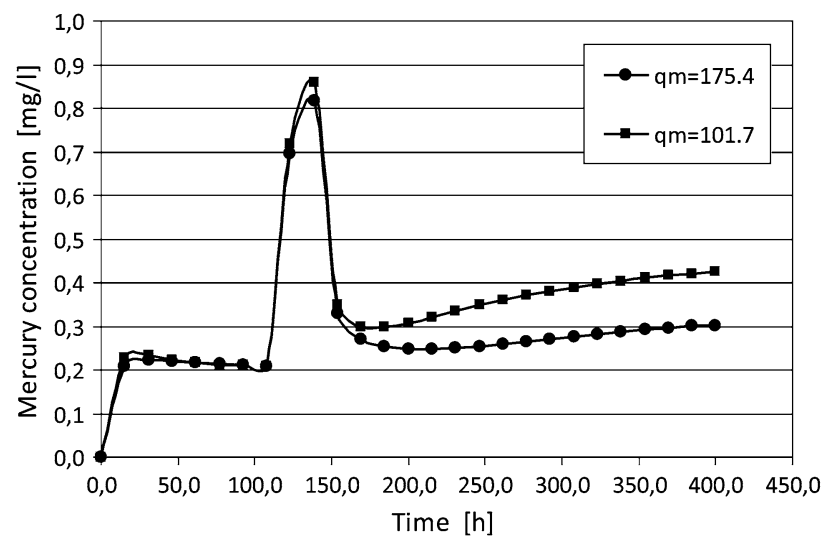

Fig. 7 Changes of the outlet mercury concentration after temporary increase of the inlet concentration; the model includes biomass growth/decay equation (Eq. 21). Simulation performed for two different types of activated carbon

mercury concentration of $0.3 \mathrm{mg} \mathrm{dm}^{-3}$, i.e. the value obtained experimentally. Hence, it is visible that if the activated carbon with smaller saturation capacity is applied in the system, fluctuations of the inlet mercury concentration causes greater damage to the active biomass, which leads to higher outlet mercury concentration. This simulation independently proves that the integration of adsorption and bioreduction processes in one apparatus leads to better efficiency of the bioremediation process. The high adsorption capacity of activated carbon provides buffer properties of the bacterial carrier and partially protects microorganisms against fluctuations of the $\mathrm{Hg}$ concentration.

In Fig. 7, there is another difference visible in comparison to Fig. 6; it concerns the first part of the curve before the concentration disturbance. If the biomass growth is described by the logistic model, the biomass concentration at the beginning of the process increases gradually. Due to this, the outlet mercury concentration initially goes up (Fig. 7) and decreases to the value of $0.2 \mathrm{mg} \mathrm{dm}^{-3}$ only when the biomass density reaches its maximum value. This effect is also more pronounced for the curve with the lower value of the sorbent saturation capacity, $q_{m}$.

It is also worth noticing that the maximum mercury outlet concentration during the simulated experiment showed in Fig. 7 is $0.8 \mathrm{mg} \mathrm{dm}^{-3}$. The calculated value is in good agreement with the experimental value of $0.7 \mathrm{mg} \mathrm{dm}^{-3}$ observed for this maximum (Fig. 2), so it may be considered as the additional verification of the mathematical model of the process.

\section{Biomass concentration distribution in the bioreactor}

According to Eq. 21, the rate of the biomass density changes depends on the local concentration of mercury.

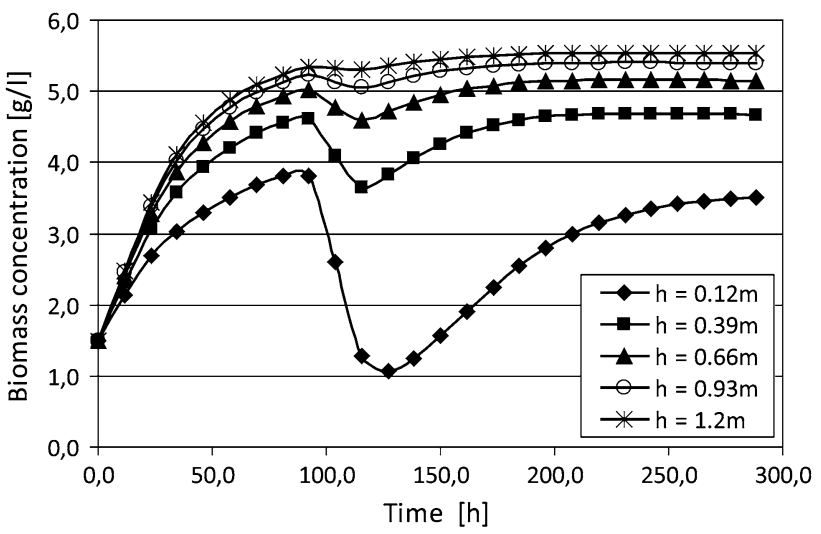

Fig. 8 Changes of the biomass concentration at different levels of the bioreactor during the temporary increase of the inlet mercury concentration from 2.5 to $10 \mathrm{mg} / \mathrm{dm}^{3}$

The latter alters gradually along the height of the bioreactor, so obviously one can observe also biomass concentration distribution in the apparatus, as there is a feedback between these two concentrations in the model. Figure 8 shows changes of the biomass concentration at five different levels of the bioreactor during the earlier described experiment of impulse $\mathrm{Hg}$ concentration disturbance at the inlet. In the figure, it is visible that during the $\mathrm{Hg}$ concentration impulse the biomass density decreases in different ways at different levels. Certainly, the greatest changes take place at the lowest level, i.e. close to the bioreactor inlet, where the mercury concentration is the highest, and at the outlet (at the fifth level), biomass concentration alters only slightly. When the inlet $\mathrm{Hg}$ concentration falls down to the initial value of $2.5 \mathrm{mg} \mathrm{dm}^{-3}$, the biomass regenerates, but does not reach the same density as it had before the disturbance. This effect is responsible for the higher value of mercury outlet concentration after the impulse disturbance experiment.

The full regeneration of biomass after the transient increase of the wastewater toxicity is possible, but it requires a lowering of the inlet mercury concentration after the experiment in comparison to the initial (nominal) value. It may be illustrated by the next two figures. In Fig. 9, the simulated response of the system to the same impulse experiment is shown, but there are two curves in the figure. One of them represents the course of the experiment, described earlier, when the inlet mercury concentration after the increase from 2.5 to $10 \mathrm{mg} \mathrm{dm}^{-3}$ goes down again to $2.5 \mathrm{mg} \mathrm{dm}^{-3}$, and the second shows the outlet mercury concentration changes when the inlet concentration after the impulse is lowered to $1.25 \mathrm{mg} \mathrm{dm}^{-3}$, i.e. to the half of the initial value. In the second case, the outlet $\mathrm{Hg}$ concentration falls down to almost $0.1 \mathrm{mg} \mathrm{dm}^{-3}$, due to more intense growth of the biomass.. In Fig. 10, the biomass density changes at different levels of the bioreactor in the 


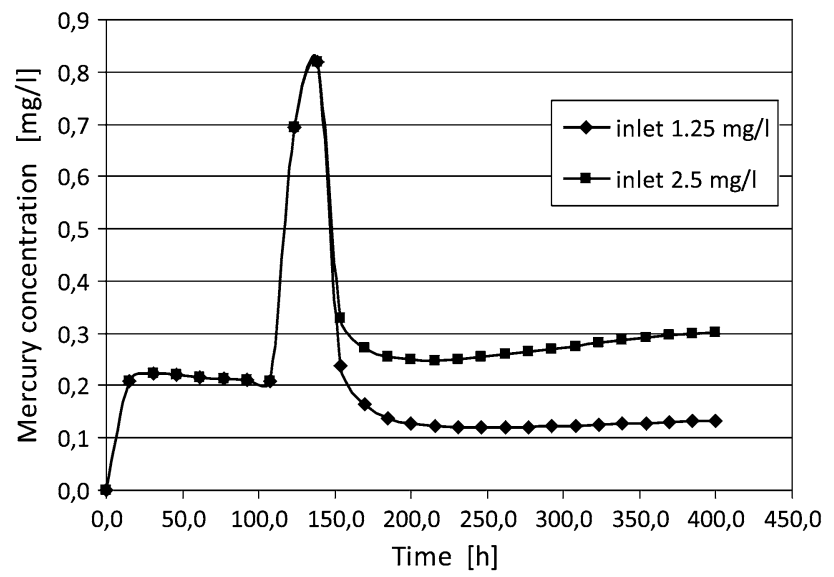

Fig. 9 Comparison of the responses of the system to the inlet mercury concentration disturbance if the final inlet concentration drops back to $2.5 \mathrm{mg} / \mathrm{dm}^{3}$ or is lowered to $1.25 \mathrm{mg} / \mathrm{dm}^{3}\left(\mu_{n}=1\right.$ / $30 \mathrm{~h}^{-1}$ )

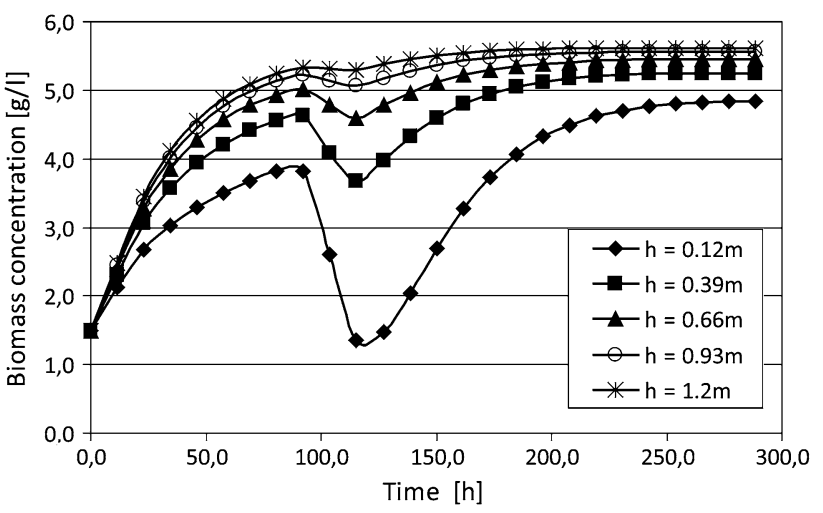

Fig. 10 Changes of the biomass concentration at different levels of the bioreactor during the temporary increase of the inlet mercury concentration from 2.5 to $10 \mathrm{mg} / \mathrm{dm}^{3}$ if the final inlet concentration drops to $1.25 \mathrm{mg} / \mathrm{dm}^{3}$

course of such modified experiment are shown. It is visible that after the $\mathrm{Hg}$ concentration impulse, the biomass fully regenerates at all bioreactor levels and its density increases to a higher value than just before the disturbance. Due to additional biomass growth, the mercury bioreduction reaction is more effective and the outlet $\mathrm{Hg}$ concentration diminishes. The regeneration and growth ability of the biomass at the time periods when the mercury concentration is lowered enables continuation of a stable bioremediation process for a long time, even if temporary concentration disturbances occur at the inlet of the bioreactor from time to time, which is a common case in industrial practice.

Figure 11 is similar to Fig. 9, but these two graphs were obtained using different values of maximum specific growth rate $\mu_{n}$. Comparison of the plots leads to the conclusion that $\mu_{n}$ affects the bioremediation process only in the initial phase of biomass growth. The only slight

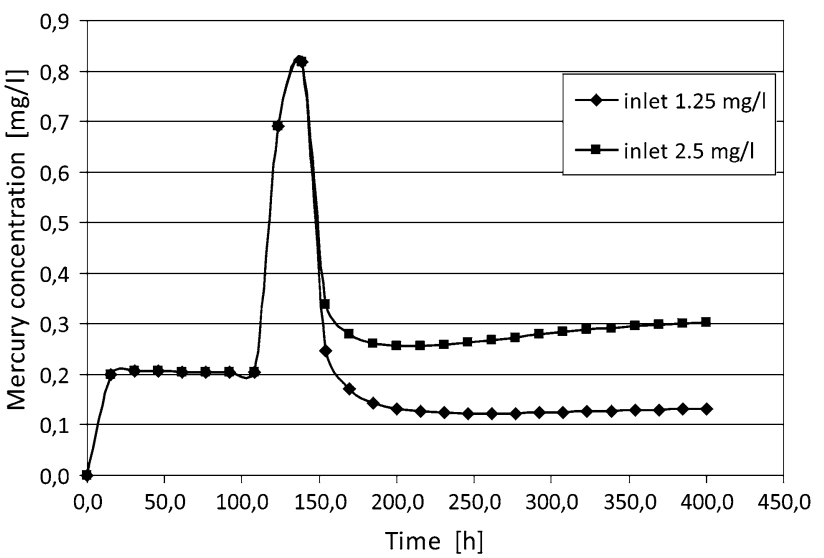

Fig. 11 Comparison of the responses of the system to the inlet mercury concentration disturbance if the final inlet concentration drops back to $2.5 \mathrm{mg} / \mathrm{dm}^{3}$ or is lowered to $1.25 \mathrm{mg} / \mathrm{dm}^{3}\left(\mu_{n}=1\right.$ / $10 \mathrm{~h}^{-1}$ )

difference between the graphs is visible in the first part of the curve, before the impulse concentration disturbance. If the $\mu_{n}$ value of $1 / 30 \mathrm{~h}^{-1}$ is applied (Fig. 9), the outlet concentration goes through a maximum due to slower growth of the bacteria at the beginning of the process, as discussed earlier. For the $\mu_{n}$ value of $1 / 10 \mathrm{~h}^{-1}$ (and higher), the biomass growth is so rapid that it does not affect the bioremediation process and the outlet mercury concentration reaches a constant value of $0.2 \mathrm{mg} \mathrm{dm}^{-3}$ as quickly as in the case of the constant biomass density (Fig. 6).

For further generalization of the model, the equation for biomass growth (Eq. 21) was modified by introducing biomass concentration into the decay term. So the modified equation (Eq. 21) may be now written as:

$\frac{d \rho_{\mathrm{bi}}}{d t}=\mu_{n}\left[\rho_{\mathrm{bi}}\left(1-\frac{\rho_{\mathrm{bi}}}{\rho_{\mathrm{bm}}}\right)-\beta \rho_{\mathrm{bi}} c_{\mathrm{A}}\right]$

or in the equivalent form:

$\frac{d \rho_{\mathrm{bi}}}{d t}=\mu_{n} \frac{\rho_{\mathrm{bi}}}{\rho_{\mathrm{bm}}}\left[\rho_{\mathrm{bm}}\left(1-\beta c_{\mathrm{A}}\right)-\rho_{\mathrm{bi}}\right]$

where $c_{A}$ again denotes the local mercury concentration in the bioreactor.

Such a form of the relation describing growth and decay of the biomass is commonly used in disinfection or sterilization processes, where the decay rate is proportional to the dose of the biocidal factor $\left(\beta c_{A}\right)$ and to the current biomass concentration $\left(\rho_{b i}\right)$, which leads to the exponential biomass decay [13]. It follows from Eq. 23 that biomass concentration is:

$\rho_{\mathrm{bi}}=\rho_{\mathrm{bm}}\left(1-\beta c_{\mathrm{A}}\right)$

so it diminishes with the increase of the local mercury concentration $c_{\mathrm{A}}$ when $\beta \neq 0$.

After taking into account the Eq. 23 in the mathematical model, the simulated response of the system to the 


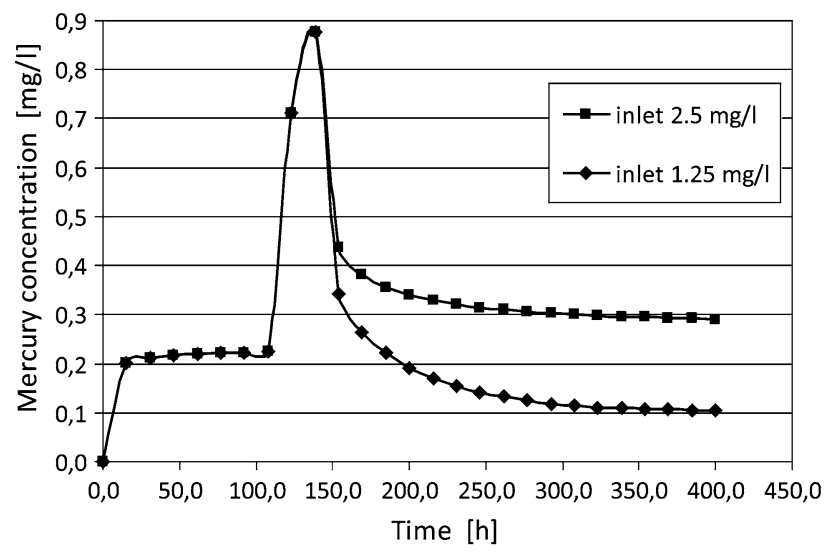

Fig. 12 Comparison of the responses of the system to the inlet mercury concentration disturbance if the final inlet concentration drops back to $2.5 \mathrm{mg} / \mathrm{dm}^{3}$ or is lowered to $1.25 \mathrm{mg} / \mathrm{dm}^{3}\left(\mu_{n}=1\right.$ / $10 \mathrm{~h}^{-1}$, kinetics of the biomass growth according to the Eq. 23)

previously described impulse concentration disturbance is presented in Fig. 12, for $\beta=3.9 g_{\text {bio }} g_{\mathrm{Hg}(\mathrm{II})}^{-1}$ and $\mu_{n}=1 /$ $30 \mathrm{~h}^{-1}$.

Comparing the curves of $\mathrm{Hg}$ concentration in Figs. 11 and 12 , it can be seen that after $\mathrm{Hg}$ disturbance at the bioreactor inlet, the outlet $\mathrm{Hg}$ concentration in both cases approach the same level of $0.3 \mathrm{mg} \mathrm{dm}^{-3}$. However, in the case of the modified equation for biomass growth and decay (Eq. 23), the shape of the curves in Fig. 12 is more consistent with the experimental data shown in Fig. 2. Hence, it may be concluded that the model including Eq. 23 for biomass growth and decay gives a good approximation of the real process.

In Figs. 13 and 14, the biomass density distribution along the bioreactor is presented for the modified model with Eq. 23 included. Comparing these figures with Figs. 8 and 10 , respectively, it is clearly visible that if the inlet

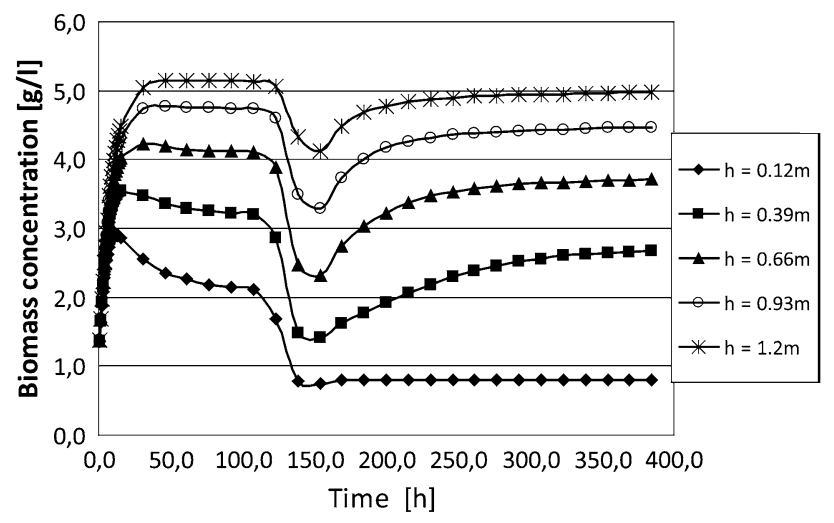

Fig. 13 Changes of the biomass concentration at different levels of the bioreactor during the temporary increase of the inlet mercury concentration from 2.5 to $10 \mathrm{mg} / \mathrm{dm}^{3}$ (kinetics of the biomass growth according to Eq. 23)

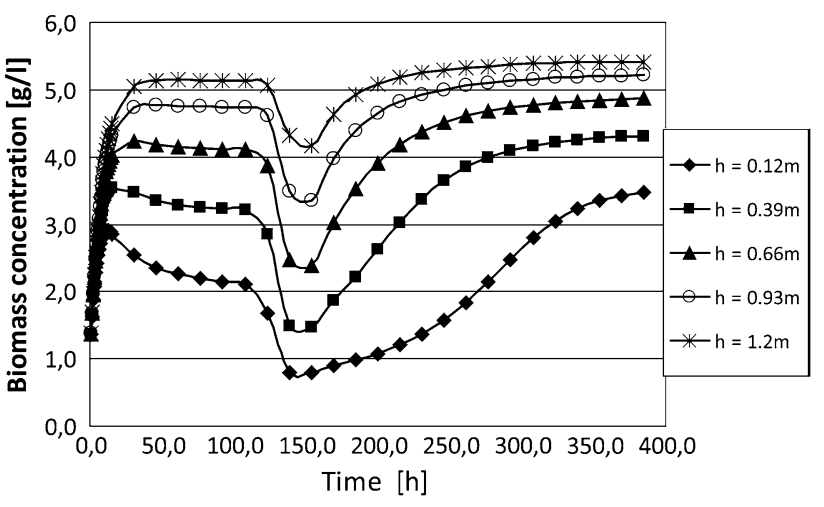

Fig. 14 Changes of the biomass concentration at different levels of the bioreactor during the temporary increase of the inlet mercury concentration from 2.5 to $10 \mathrm{mg} / \mathrm{dm}^{3}$ if the final inlet concentration drops to $1.25 \mathrm{mg} / \mathrm{dm}^{3}$ (kinetics of the biomass growth according to Eq. 23)

mercury concentration after the impulse disturbance goes back to the nominal value of $2.5 \mathrm{mg} \mathrm{dm}^{-3}$, the biomass density does not achieve the initial value from before the disturbance at any height of the bioreactor. This results in increased mercury content in the outlet stream, which is visible in Fig. 12.

Figure 14 in turn illustrates biomass concentration distribution in the variant of experiment when the final inlet mercury concentration is lowered to $1.25 \mathrm{mg} \mathrm{dm}^{-3}$, which enabled the more intensive biomass growth and then the decrease of the outlet mercury concentration below the initial value of $0.2 \mathrm{mg} \mathrm{dm}^{-3}$ (Fig. 12).

\section{Final remarks and conclusions}

The presented mathematical model of the integrated bioremediation process reflects the properties of the real system quite well. It takes into account many phenomena observed in the course of the process conducted in an industrial environment. Among them are the following:

- deactivation of biomass as a result of a substrate (ionic mercury) toxicity;

- the ability of biomass to regenerate after a temporary significant increase of the inlet mercury concentration;

- the dominant role of the mercury bioreduction reaction in comparison to the $\mathrm{Hg}(\mathrm{II})$ adsorption onto activated carbon in the final effect of the bioremediation process;

- significant influence of the liquid flow rate on the process of biological reduction of $\mathrm{Hg}(\mathrm{II})$;

- great influence of the increased toxicity of wastewater due to $\mathrm{Hg}$ concentration disturbance at the bioreactor inlet on the biomass growth/decay rate and biomass density distribution along the bioreactor. 
It is also worth noting that numerical simulation of the process proved the positive, synergistic effect of the integration of mercury sorption and bioreduction in one apparatus. In the system with higher sorption capacity of the fixed bed where the bacteria were immobilized, the response to the rapid mercury concentration changes was milder and the biomass was better protected against the toxicity of the mercury ions.

As proved in the discussion, the selective and rational parametric sensitivity analysis of the model and comparison of the simulation results with the available experimental data obtained in an industrial bioreactor enabled practical verification of the proposed model of the process. The presented model with the experimentally verified parameters may be used for prediction of the behavior of the system in a case of failure or emergency and may also be applied for designing of any modifications of the bioreactor, and especially for scaling it up.

Acknowledgments This work was supported by grant No. R14 006 02 from the Ministry of Science and Higher Education of Poland.

Open Access This article is distributed under the terms of the Creative Commons Attribution Noncommercial License which permits any noncommercial use, distribution, and reproduction in any medium, provided the original author(s) and source are credited.

\section{References}

1. Eurochlor (2010) Chlorine Industry Review 2008-2009. http://www.eurochlor.org

2. von Canstein H, Li Y, Timmis KN, Deckwer WD, WagnerDoebler I (1999) Appl Environ Microbiol 65:5279

3. Gluszcz P, Zakrzewska K, Ledakowicz S, Wagner-Doebler I (2008) Chem Pap 62:232

4. Gluszcz P, Ledakowicz S, Wagner-Doebler I, Janiszewska I, Boruta D (2009) Chem Rev 88/12:1352

5. Gluszcz P, Ledakowicz S, Wagner-Doebler I (2010) In: Pawłowski L, Dudzińska M, Pawłowski A (eds) Environmental engineering III. Taylor \& Francis, London

6. Yano T, Koga S (1969) Biotechnol Bioeng 11:139

7. FLUENT@ v.6.1 (2002) Fluent user guide

8. Gluszcz P, Ledakowicz S, Petera J, Deckwer WD (2007) Chem Biochem Eng Q 21:307

9. Perry RH (2001) Chemical engineer's handbook. McGraw Hill, NY

10. Ledakowicz S, Wagner-Doebler I, Deckwer WD (2004) Biotechnology 3:106

11. Nielsen J, Villadsen J, Liden G (2003) Bioreaction engineering principles. Kluwer Academic Press, NY

12. Blanch H, Clark D (2003) Biochemical engineering. Marcel Dekker Inc, NY

13. Kowalski WJ (2005) Aerobiological engineering handbook. McGraw-Hill, NY 